\title{
Homozygous myotonic dystrophy: clinical and molecular studies of three unrelated cases
}

Loreto Martorell, Isabel Illa, Jordi Rosell, Javier Benitez, Maria José Sedano, Montserrat Baiget

\begin{abstract}
We report the clinical and molecular study of three unrelated homozygous myotonic dystrophy patients. In the first family, the homozygous patient shows the classical form of the disease with two DM alleles of very different expansion sizes (1000 and 60 repeats). In the second family, the homozygous patient is mildly affected and carries a minimally expanded allele (64 repeats) and a "normal" allele (38 repeats) that increases in size when transmitted. Such an intergenerational expansion of an allele in this range of repeats has not been reported to date. The third homozygous case has late onset bilateral cataracts as the only symptom. She has two minimally expanded alleles (51 and 120 repeats) that showed different intergenerational enlargement during transmission to the next generation. $(\mathfrak{F}$ Med Genet 1996;33:783-785)
\end{abstract}

Unitat de Genètica Molecular, Hospital Sant Pau, Avda Pare Claret 167, 08025 Barcelona, Spain L Martorell

M Baiget

Unitat de Patología Neuromuscular, Hospital Sant Pau, Avda Pare Claret 167, 08025 Barcelona, Spain I Illa

Sección de Genètica, Hospital Son Dureta, Palma de Mallorca, Spain

J Rosell

Servicio de Genética, Fundación Jimenez Diaz, Madrid, Spain J Benitez

Servicio de Neurología, Hospital General Yagüe, Burgos, Spain M J Sedano

Correspondence to: Dr Baiget.

Received 5 February 1996 Revised version accepted for publication 15 April 1996 was lethal in DM or at least so severe that it would lead to intrauterine death. ${ }^{1}$ However, in 1993, we reported two sisters who were asymptomatic for the disease in spite of being homozygous for the DM expansion. ${ }^{11} \mathrm{~A}$ homozygous patient with a more severe phenotype than would be predicted by his repeat size alone was reported in $1994 .{ }^{12}$ We report the clinical and molecular study of three additional unrelated DM homozygous patients.

In the present study, for CTG expansion analyses, genomic DNA was digested with $E c o$ RI, electrophoresed on a $0.6 \%$ agarose gel, and hybridised with probe cDNA25. Amplification across the CTG repeat region by PCR was performed with a pair of oligonucleotide primers flanking the region, as described elsewhere, ${ }^{4}$ and radiolabel was added to the PCR samples for visualisation on 5\% polyacrylamide sequencing gels exposed to hyperfilmMP. ${ }^{11}$ Haplotype analyses were performed using the following markers: $\mathrm{CKMM}^{13}$ D19S63, ${ }^{14}$ D19S51, ${ }^{15}$ and p37.1,${ }^{16}$ according to standard procedures. ${ }^{17}$

The protocol for this study was approved by the Hospital de la Santa Creu i Sant Pau Ethical Committee and consent was obtained from the participating patients and their relatives. In family 1 (fig 1), the proband (II.6) is a 54 year old woman with a severe clinical form of DM. She was the sixth child of consanguineous parents. Three of her six male sibs (II.1, II.2, and II.5) were clinically diagnosed as having DM. Subjects II.3, II.4, and II.7 showed no symptoms of DM. Autoradiography (fig 2) shows the presence of the DM associated expansions in the DNA samples of II.5 $(11 \mathrm{~kb})$ and II.6 (10.1 and $13 \mathrm{~kb})$ and normal bands of 9 and $10 \mathrm{~kb}$ in II.7. Analysis of the PCR products confirmed the presence of a DM allele with 60 repeats and the absence of normal alleles in DNA from the proband II.6 (fig 3). Study of the DNA from blood cells of II. 6 over a two year period showed that the DM allele with 60 repeats had not changed in size, while an increase of 166 repeats has occurred in the DM allele with an initial size of $13 \mathrm{~kb}$ (data not shown).

In family 2 (fig 1), the DM homozygous case is an 84 year old male (I.1) who, like his sister (I.3) aged 72, had cataracts as the only symptom of DM. By history, their parents were healthy and non-consanguineous. The proband's oldest daughter (II.1) is a 43 year old woman with a classical form of DM. The 
Family 1
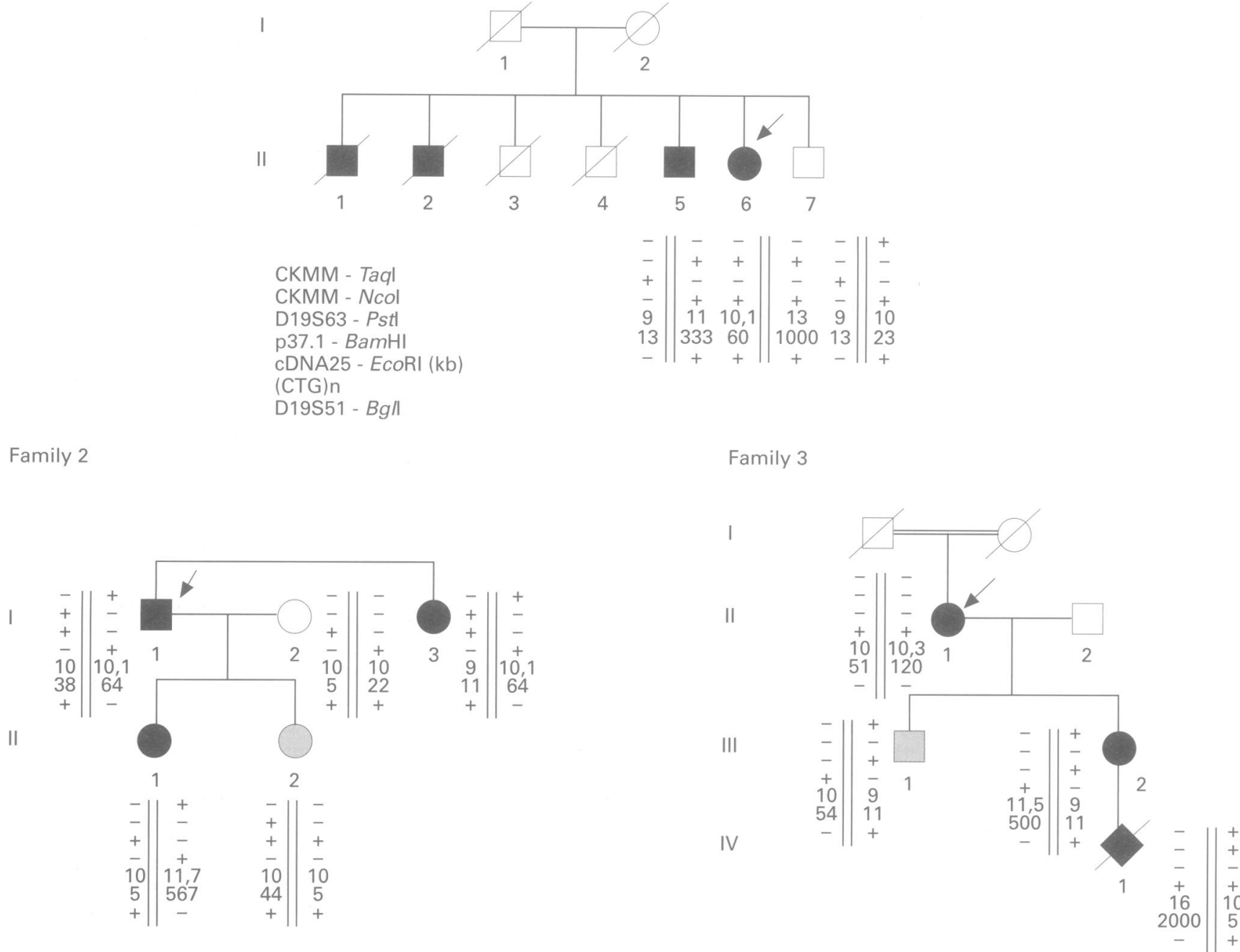

Figure 1 Pedigrees and haplotypes of the families. Black symbols indicate DM patients and hatched symbols indicate asymptomatic DM carriers. The DM homozygous patients are arrowed. Haplotypes comprise typings (top to bottom, centromere to telomere) CKMM/TaqI, NcoI, D19S63/PstI, p37.1/BamHI, cDNA25/EcoRI, D19S51/BgII.

younger daughter (II.2) is a 31 year old woman with no symptoms or signs of the disease on neurological examination. No myopathic motor units or myotonia were found on EMG of proximal and distal muscles.

Subject I.1 had alleles with 38 and 64 CTG repeats. I. 3 had one normal allele (11 CTG repeats) and a expanded allele (64 repeats). II. 1 had one allele with five repeats by PCR and a second allele of $11.7 \mathrm{~kb}$ on Southern blot. II. 2 had alleles with five and 44 CTGs (figs 2 and 3). Segregation of marker alleles of
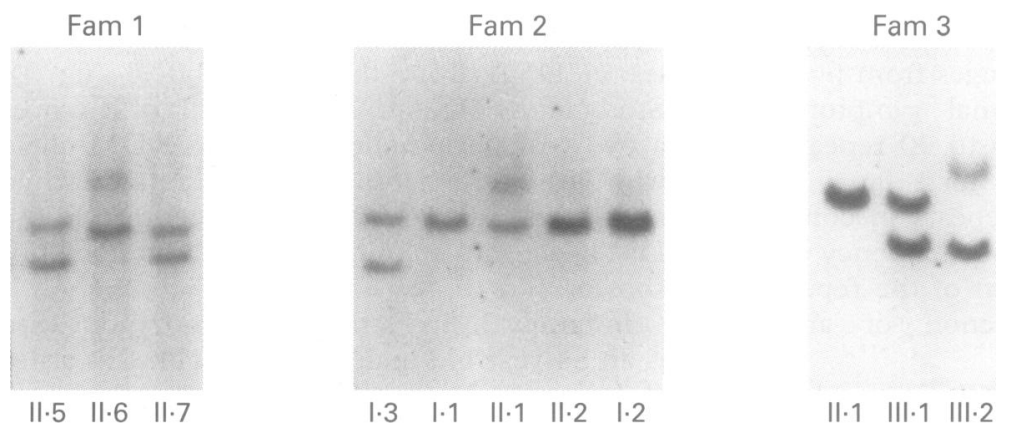

Figure 2 Southern blot of EcoRI digested genomic DNA, probed with cDNA25. Normal subjects are either homozygous or heterozygous for the 10 and $9 \mathrm{~kb}$ alleles. Affected subjects have one of these two bands plus a second band of $>10 \mathrm{~kb}$. Samples are numbered as in fig 1 . the genomic region containing the DM gene was performed in order to determine whether the allele with 44 CTGs seen in II.2 was the result of a reverse mutation in the paternal allele with 64 CTGs or of an expansion of the paternal allele of 38 CTGs. The result of this segregation analysis (see haplotypes in fig 1) indicates that II. 1 has inherited the paternal $\mathrm{DM}$ allele with an intergenerational expansion of approximately $1.6 \mathrm{~kb}$, while II. 2 has inherited a "predisposed" allele with 38 CTGs able to increase six CTGs during transmission, in such a way that II.2 is a carrier of a premutated allele.

In family 3 the homozygous case (II.1) is a 55 year old woman born to healthy, consanguineous parents. Late onset bilateral cataracts are the only symptom of DM. Her son (III.1), aged 32 , is clinically normal. Her daughter (III.2), aged 28, has a classical form of DM; she became pregnant two years ago and requested first trimester prenatal diagnosis. As an expanded allele of approximately 2000 repeats was detected in the fetal DNA, she decided to terminate the pregnancy.

The results of DNA analysis in the family are shown in figs 2 and 3. II.1 had two minimally expanded alleles of 51 and 120 repeats. As this 
woman, born to consanguineous parents, is homozygous for all the markers tested, we were unable to determine which DM allele she had transmitted to her progeny. Probably, III.1 inherited the allele with $51 \mathrm{CTG}$ that enlarges three CTGs during transmission and III.2 inherited the DM allele with 120 CTGs that increased four times its size during transmission.

The classical definition of dominance states that homozygotes and heterozygotes for a given defect are phenotypically indistinguishable. In DM, homozygotes do not differ in clinical expression from typical DM heterozygotes, indicating that DM displays complete phenotypic dominance. Among the six cases homozygous for the DM gene analysed to date, there is at least one representative of each of the different diagnostic categories seen in DM carriers: a congenitally affected man with a more severe phenotype than would be predicted by repeat size alone, ${ }^{12}$ a classical form of $\mathrm{DM}$, such as case 1 in this report, minimal signs of the disease, such as cases 2 and 3, and finally the two asymptomatic sisters previously reported. ${ }^{11}$

The fact that five out of six homozygous cases described were from consanguineous families should be kept in mind when genetic counselling is given in countries where consanguinity is not unusual.

In the normal population, the CTG repeat is polymorphic and varies between five CTGs at the lower end of the length spectrum to 40

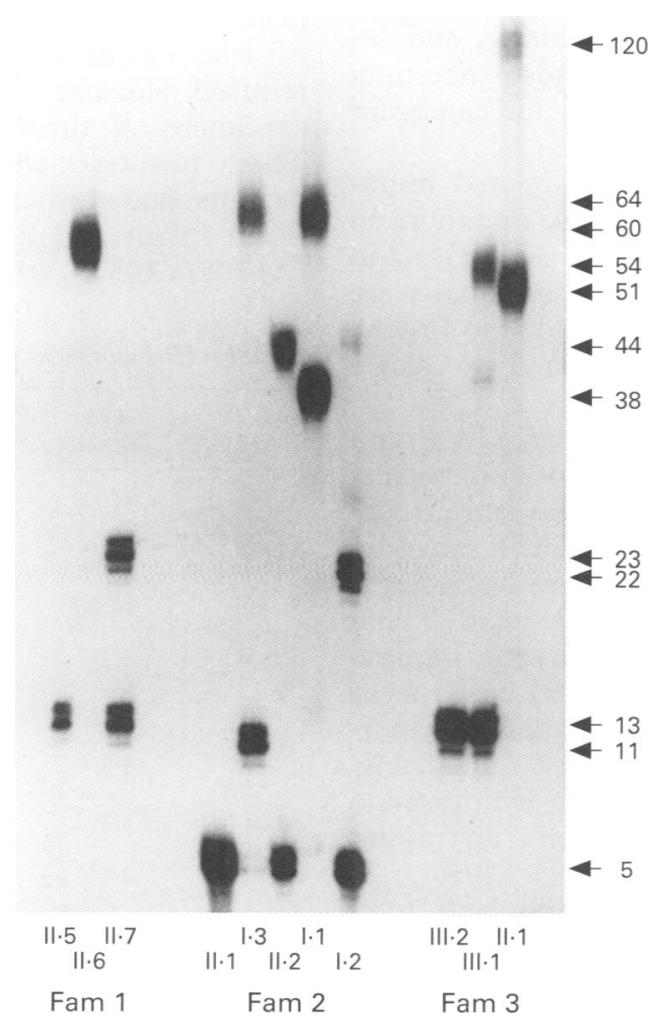

Figure 3 Radiolabelled PCR products obtained from the amplification of the CTG repeat region on a $5 \%$ polyacrylamide gel. Repeat sizes were estimated by comparison to an M13 sequencing ladder. Samples are numbered as in fig 1.
CTGs at the upper limit. Richards et $a l^{18}$ suggested that there may be a pool of subjects with repeat numbers in the upper normal range whose descendants are at an increased risk of subsequent mutation owing to the relationship between copy number and instability. Imbert $e t$ $a l^{19}$ also proposed that the large normal size alleles with greater than 19 CTGs may have significant instability and thus may be the predisposing alleles for DM mutations. Case 2 in the present report is a good example of a predisposing allele: he had transmitted an allele of 38 CTGs that increased several repeats in size when transmitted.

Even if the incidence of such cases is low at the DM locus, the larger copy number within the normal range seems to have a greater chance of progressing to the mutation range of repeats in successive generations.

In summary, our results emphasise the usefulness of molecular studies in the identification of DM homozygotes, a state not so infrequent as previously thought.

We thank Dr T Ashizawa for kindly reviewing this manuscript. This work was supported by a grant $(94 / 0350)$ from the Fondo de Investigaciones de la Seguridad Social, Ministerio de Sanidad y Consumo, Spain. We thank Professor K Johnson for kindly supplying the probe cDNA25, Dr A Valiente for sending samples of one family, and $M$ Cornet for her technical assistance.

1 Harper PS. Myotonic dystrophy. Saunders, Philadelphia: Saunders, 1989

2 Aslanidis C, Jansen G, Amemiya C, et al. Cloning of the essential myotonic dystrophy region and mapping of the putative defect. Nature 1992;355:548-50.

3 Buxton J, Shelbourne P, Davies J, et al. Detection of an unstable fragment of DNA specific to individuals with myotonic dystrophy. Nature 1992;355:547-8.

4 Brook JD, McCurrach ME, Harley HG, et al. Molecular basis of myotonic dystrophy: expansion of a trinucleotide basis of myotonic dystrophy: expansion of a trinucleotide (CTG) repeat at the 3 end of a transcript encodin

5 Fu YH, Pizzuti A, Fenwick RG, et al. An unstable triplet repeat in a gene related to myotonic muscular dystrophy. repeat in a gene related to
Science $1992 ; 255: 1256-8$.

6 Harley HG, Brook JD, Rundle SA, et al. Expansion of an unstable DNA region and phenotypic variation in myotonic dystrophy. Nature 1992;355:545-6

7 Mahadevan M, Tsilfidis C, Sabourin L, et al. Myotonic dystrophy mutation: an unstable CTG repeat in the $3^{\prime}$ untranslated region of the gene. Science 1992;255:1253-5.

8 Melchionda S, Cobo A, Gennarelli M, et al. Expansion of the myotonic dystrophy gene in Italian and Spanish patients. F Med Genet 1992;29:789-90.

9 Lavedan C, Hofmmann-Radvanyi $\mathrm{H}$, Shelbourne $\mathrm{P}$, et al. Myotonic dystrophy: size- and sex-dependent dynamics of CTG meiotic instability and somatic mosaicism. $A m \mathcal{F}$ Hum Genet 1993;52:875-83.

10 Cobo AM, Baiget M, López de Munain A, et al. Sex-related difference in intergenerational expansion of myotonic dystrophy gene. Lancet 1993;341:1159-60.

11 Cobo A, Martinez JM, Martorell L, et al. Molecular diagnosis of homozygous myotonic dystrophy in two asymptomatic sisters. Hum Mol Genet 1993;2:711-15.

12 Roeder E, Jain K, Timchenko L, et al. Homozygous myotonic dystrophy. Am f Hum Genet Suppl 1994;55:A23.

13 Brunner HG, Korneluk RG, Coerwinkel-Driessen M, et al. Myotonic dystrophy is closely linked to the gene for muscle-type creatine kinase (CKMM). Hum Genet 1989; 81:308-10.

14 Brook JD, Harley HG, Walsh KV, et al. Identification of new DNA markers close to myotonic dystrophy locus. $\mathcal{F}$ Med Genet 1991;28:84-8.

15 Johnson K, Shelbourne P, Davies J, et al. A new polymorphic probe which defines the region of chromosome 19 probe which defines the region of chromosome 19
containing the myotonic dystrophy locus. Am f Hum Genet containing the myotor

16 Korneluk RG, MacKenzie AE, Nakamura Y, et al. A reordering of human chromosome 19 long arm DNA markers and identification of markers flanking the markers and identification of markers flanking
myotonic dystrophy locus. Genomics 1989;5:596-604.

17 Sambrook J, Frisch EF, Maniatis T. Molecular cloning: a laboratory manual. 2nd ed. New York: Cold Spring Harbour Laboratory Press, 1989.

18 Richards R, Sutherland G. Dynamic mutations: a new class of mutations causing human disease. Cell 1992;70:709-12.

19 Imbert G, Kretz C, Johnson K, Mandel JL. Origin of the expansion mutation in myotonic dystrophy. Nature Genet 1993;4:72-6. 